\title{
TRICOBEZOAR GÁSTRICO
}

\author{
GASTRIC TRICHOBEZOAR
}

\section{Valdinaldo Aragão de Melo, TCBC-SE ${ }^{1}$ \\ Eduardo Góis Cardoso ${ }^{2}$ \\ Gustavo Barreto de Melo ${ }^{3}$}

\section{INTRODUÇÃO}

Bezoar pode ser definido como impactação de material estranho no interior do trato digestivo, originada a partir da ingestão de cabelos, pêlos, fibras vegetais e outros alimentos não-absorvíveis ${ }^{1}$.

Os bezoares podem ser divididos em fitobezoar (acúmulo de fibras ou sementes de vegetais), tricobezoar (cabelo), tricofitobezoar (mistura dos anteriores), lactobezoar (leite coagulado), litobezoar (pedras) e outros bezoares de origens variadas ${ }^{1-3}$.

Sendo causadores de diversos distúrbios digestivos, os bezoares adquiriram importância clínica. Devido a isso e à relativa raridade, este artigo descreve um caso de tricobezoar gástrico.

\section{RELATO DO CASO}

Uma paciente de 16 anos, estudante atendida com história de tricotilomania há mais ou menos cinco meses. A comprovação clínica de alopecia traumática foi feita pelo dermatologista.

Ela não apresentava queixas digestivas, mas, diante do comportamento bizarro e sua freqüente associação com a tricofagia, foi solicitada seriografia do Esôfago, Estômago e do Duodeno (Figura 1). Esta demonstrou estômago dilatado com grande quantidade de resíduos, sugerindo bezoar. Através de Endoscopia Digestiva Alta visualizou-se grande quantidade de cabelo na grande curvatura gástrica e região pré-pilórica, ocupando dois terços do espaço gástrico.

Durante a anamnese feita pelo cirurgião referiu desorganização afetiva familiar por ausência da figura paterna. Os únicos hábitos e vícios citados foram a tricotilomania e a tricofagia.

Ao exame físico, apresentou-se com bom estado geral, obesa, eupnéica, anictérica, afebril, normotensa e com mucosas descoradas (+/++++) e hidratadas. Apresentava áreas com desigualdade no comprimento dos fios de cabe-

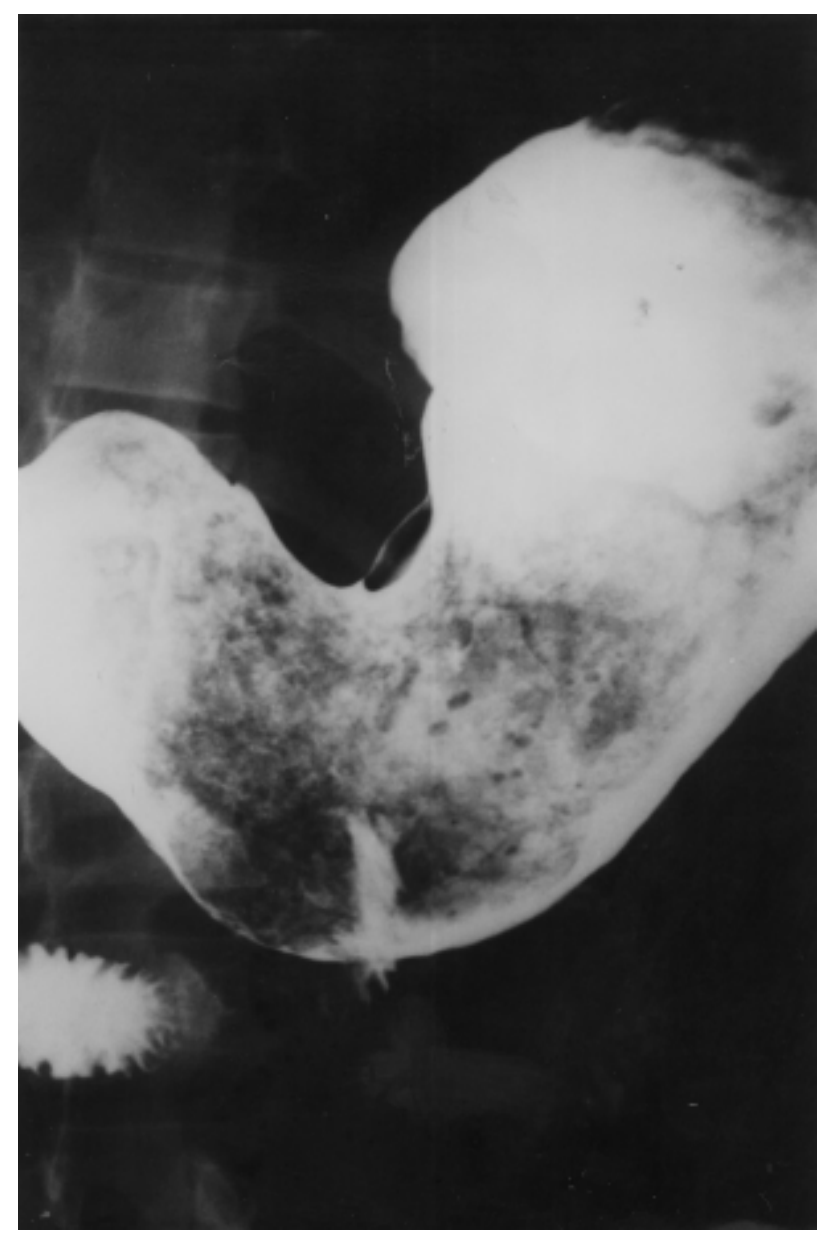

Figura 1 - Seriografia de Estômago, com visualização de grande bezoar.

lo. Seu abdome era globoso, à custa de grande panículo adiposo, flácido, indolor e ausência de massas ou visceromegalias à palpação superficial e profunda.

1. Professor Adjunto do Departamento de Medicina da UFSE.

2. Professor Assistente do Departamento de Medicina da UFSE.

3. Acadêmico de Medicina da UFSE. Bolsista do PIBIC/CNPq/UFSE.

Recebido em 05/07/2001

Aceito para publicação em 22/11/2001

Trabalho realizado no Hospital Universitário da Universidade Federal de Sergipe 
Os exames laboratoriais mostraram hipocromia com hemoglobina de $10,7 \mathrm{~g} / \mathrm{dl}$, anisocitose, linfopenia e neutropenia no hemograma. Os demais resultados apresentaram-se normais.

Através de gastrotomia anterior, foi extraído tricobezoar com $1.100 \mathrm{~g}$ e $17 \mathrm{~cm}$ em seu maior diâmetro (Figura 2). Durante a permanência hospitalar foi medicada com cefalotina $1 \mathrm{~g}$ IV a cada seis horas.

No pós-operatório, queixou-se de dor na ferida operatória, apresentou episódios de vômito, febre e eliminação de secreção piosserossanguinolenta em terço médio distal da incisão. Recebeu alta após seis dias, sendo encaminhada para o ambulatório de Psiquiatria e Psicologia.

\section{DISCUSSÃO}

Entre os bezoares, o mais comum é o fitobezoar. Consiste de celulose não-digerida, lignina, hemicelulose e outros derivados de frutas e vegetais. É mais frequiente em pacientes com história de cirurgia gástrica e está presente em aproximadamente $20 \%$ dos pacientes que se submeteram à antrectomia ${ }^{2}$.

Já os tricobezoares são mais raros e mais freqüentes em jovens. Segundo DeBakey $(1938)^{4}, 80 \%$ dos tricobezoares ocorrem em pessoas com idade inferior a 30 anos. A distribuição por sexo é desigual: $91,4 \%$ dos pacientes são do sexo feminino.

A sintomatologia do tricobezoar é inespecífica, insidiosa e gradual. As principais manifestações clínicas são dor abdominal, náuseas e vômitos, desconforto abdominal, anorexia e perda de peso ${ }^{4}$. Tricofagia, alopecia, halitose e distúrbios psiquiátricos em $9 \%$ das pessoas analisadas estão associados ${ }^{4}$. Ao exame físico, pode ser detectada

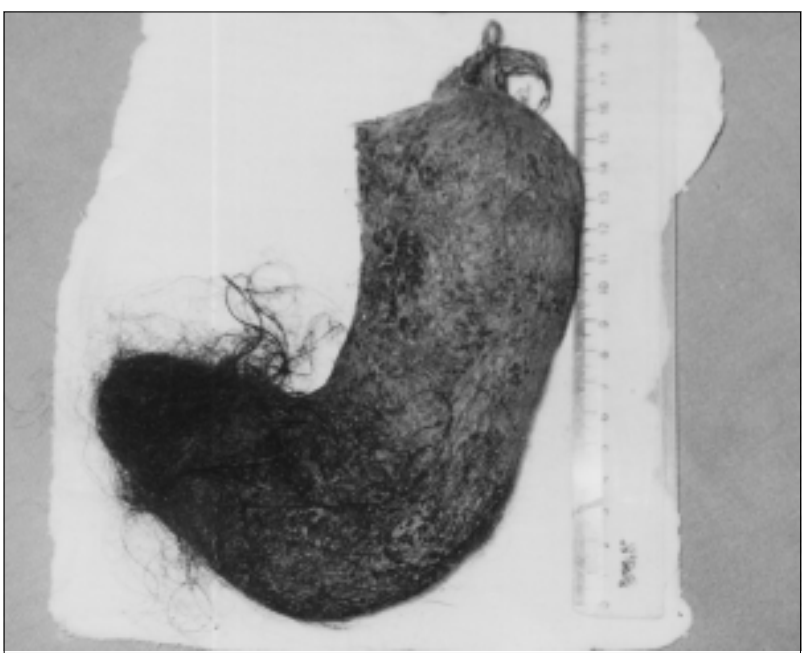

Figura 2 - Tricobezoar, pesando $1.100 \mathrm{~g}$ e medindo $17 \mathrm{~cm} \mathrm{em}$ seu maior diâmetro.

massa palpável e endurecida na região epigástrica ${ }^{5}$. O caso descrito foi assintomático e referia antecedentes de distúrbios psiquiátricos.

O exame clínico é importante para o diagnóstico de tricobezoar. Para confirmação, podem ser realizadas radiografias simples e contrastadas, endoscopia, ultra-sonografia e tomografia computadorizada ${ }^{2}$.

No tratamento dos bezoares, pode-se tentar a extração por via endoscópica ou mesmo a fragmentação mecânica ou com terapia enzimática ${ }^{2}$. Em relação aos tricobezoares, como foi feito no caso apresentado, o tratamento de escolha é cirúrgico, através de gastrotomia anterior.

\begin{abstract}
Bezoar is a foreign body in the digestive tract originated from ingestion of varied substances, mainly vegetal hair or coats, staple fibers among others. We present a case of a 16-year-old female with trichotillomania history of approximately 5 months, diagnosed through clinical evidence of traumatic alopecia made by her dermatologist. Though asymptomatic the presence of tricobezoar was suspected and confirmed through digestive seriography and high digestive endoscopy. The patient was operated on for gastrotomy and removal of bezoar, with good postoperative follow-up, except for surgical wound infection.
\end{abstract}

Key Words: Gastric Trichobezoar. Trichotillomania. Foreign body.

\title{
REFERÊNCIAS
}

1. Spadella CT, Saad-Hossne R, Saad LHC. Tricobezoar gástrico: Relato de caso e revisão da literatura. Acta Cir Bras, 1998, 13(2):110-115.

2. Phillips MR, Zaheer S, Drugas GT. Gastric Trichobezoar: Case Report and Literature Review. Mayo Clin Proc, 1998, 73: 653-656.

3. Melo VA, Godoy AQ, Ceneviva R. Obstrução intestinal por ingestão de pedras. Rev Ass Med Brasil, 1981, 27: 203.

4. DeBakey M, Ochsner A. Bezoars and concretions: a comprehensive review of the literature with analysis of 303 collected cases and a presentation of 8 additional cases. Surgery, 1939, 5: 132-160.
5. Lamerton AJ. Trichobezoar: two case reports - A new physical sign. Am J Gastroenterol, 1984, 79: 354.

Endereço para correspondência:

Valdinaldo Aragão de Melo

Rua Álvaro Brito, 14, apto. 301, Praia 13 de Julho 49020-400 - Aracaju-SE

email:vamelo@infonet.com.br 